\title{
Sensitization, Duration, and Pharmacological Blockade of Anxiety-Like Behavior Following Repeated Ethanol Withdrawal in Adolescent and Adult Rats
}

\author{
Tiffany A. Wills, Darin J. Knapp, David H. Overstreet, and George R. Breese \\ Neurobiology Curriculum (TAW, GRB, DJK), Bowles Center for Alcohol Studies (DJK, DHO, GRB), \\ Departments of Psychiatry (DJK, DHO, GRB) and Pharmacology (GRB), University of North \\ Carolina, School of Medicine, Chapel Hill, North Carolina.
}

\begin{abstract}
Background-Repeated ethanol withdrawal sensitizes anxiety-like behavior in adult rats and causes anxiety-like behavior and decreased seizure thresholds in adolesnt rats. Current experiments determined if adolescent rats exhibit sensitized anxiety-like behavior, the duration of this effect, if drug pretreatments blocked these effects, and if these effects differed from those seen in adults.

Methods-Male adolescent rats received three 5-day cycles of 2.5\% ethanol diet (ED) separated by two 2-day withdrawal periods, continuous 15 days of $2.5 \% \mathrm{ED}$, or a single 5-day cycle of $2.5 \%$ ED. Male adult rats received three 5-day cycles of either $2.5 \%$ or $3.5 \% \mathrm{ED}$. These groups were tested 5 hours into the final withdrawal for social interaction (SI) deficits (an index of anxiety-like behavior). Ethanol intake was monitored throughout and blood concentrations were obtained from separate groups of rats. Additionally, adolescent rats were tested for SI 1, 2, 7, 14, and 18 days and adults 1 and 2 days after the final withdrawal. Some adolescent rats were also pretreated with the $\mathrm{CRF}_{1}$ antagonist $\mathrm{CP}-154,526$, the $5-\mathrm{HT}_{1 \mathrm{~A}}$ agonist buspirone, or the benzodiazepine receptor antagonist flumazenil during the first 2 withdrawals.
\end{abstract}

Results-SI was reduced in adolescent rats following repeated withdrawals of $2.5 \% \mathrm{ED}$ while neither a continuous or single cycle ED exposure caused this effect. Adult rats also had reduced SI following repeated withdrawals from both $2.5 \%$ and $3.5 \% \mathrm{ED}$. This effect was present up to 1 week following the final withdrawal in adolescents but returned to baseline by 1 day in adults. CP-154,526, buspirone, or flumazenil prevented this reduction in SI in adolescent rats.

Conclusions-Adolescent rats exhibit sensitized anxiety-like behavior following repeated withdrawals at ED concentrations similar to those used in adults. However, this effect is longer lasting in adolescent rats. Drugs modulating CRF, 5-HT, or GABA systems during initial withdrawals prevent the development of anxiety-like behavior otherwise manifest during a final withdrawal in adolescent rats.

\section{Keywords}

Repeated Ethanol Withdrawal; Sensitization; Anxiety; Development; Adolescents

Adolescence is Known to be a time of increased risk-taking behaviors, which includes increased use of alcohol. Recent statistics showed that $73 \%$ of high school students had used

\footnotetext{
Copyright $(92008$ by the Research Society on Alcoholism.

Reprint requests: Darin J. Knapp, PhD, Bowles Center for Alcohol Studies, CB\#7178, University of North Carolina at Chapel Hill, Chapel Hill, NC 27599; Fax: 919-966-5679; darin_knapp@ med.unc.edu.
} 
alcohol by the time they graduated (Johnston et al., 2007). Adolescents are also known to consume alcohol in a "binge-like" pattern and likely experience repeated ethanol withdrawals (Hiller-Sturmhöfel and Swartzwelder, 2004/2005). Of considerable concern is the fact that the strongest predictor of alcohol dependence in adulthood is the use of alcohol before the age of 14 (Grant, 1998). Furthermore, the dependency course (time between initial use and dependence) is more rapid in adolescents than adults (Clark et al., 1998). While considerable attention is currently being paid to adolescent alcohol use and abuse, less work is being done on the consequences of chronic ethanol exposure. In particular, further investigations are needed on the consequences of more "naturalistic" or cyclic/repeated patterns of chronic ethanol abuse known to characterize intake and differentially impact on withdrawal in adult humans and rodents.

Clinical evidence first suggested that increased alcohol withdrawal symptoms (including seizures) occurred following multiple detoxifications (Ballenger and Post, 1978). Later work illustrated that an increased susceptibility for withdrawal sensitization or "kindling" was also produced after repeated ethanol withdrawals in rodents (Becker and Hale, 1993; Kokka et al., 1993; McCown and Breese, 1990). Further investigations demonstrated that other symptoms of withdrawal (i.e., anxiety) could undergo a kindling-like process in adult rodents (Breese et al., 2004; Overstreet et al., 2002). In these experiments, it was shown that withdrawal from three 5-day cycles of ethanol diet induced anxiety-like behavior, which was not produced by withdrawal from 15 continuous days of ethanol exposure (Overstreet et al., 2002). The production of anxiety-like behavior only following repeated ethanol withdrawals demonstrated that the pattern of ethanol exposure, independent of the amount of ethanol per se, was important in sensitizing anxiety-like behavior (Breese et al., 2005a).

Recent work illustrated that adolescent rats have increased anxiety-like behavior and reduced seizure thresholds following exposure to repeated ethanol withdrawals (Wills et al., 2008). While behavioral comparisons indicated an increased vulnerability to these effects in adolescents, increased ethanol intake and differential blood ethanol concentrations (BECs) could have accounted for age-related differences. Nonetheless, these experiments showed that adolescent rats displayed at least as much withdrawal related behaviors as adult rats. This effect was distinct from previous investigations where adolescent rats had either reduced or absent withdrawal-related behaviors compared to adults (Acheson et al., 1999; Doremus et al., 2003; Varlinskaya and Spear, 2004). While a number of experimental differences could account for these differences, including route of ethanol administration, species used, age of behavioral testing, and test used to measure anxiety, a potentially critical factor is the use of cycled chronic ethanol exposure (Wills et al., 2008), a variable not employed in these other investigations. While it has been illustrated that adolescent rats can exhibit anxiety-like behavior following repeated withdrawals, it was not established whether repeated ethanol withdrawals actually sensitized anxiety-like behaviors, as has been shown in adult rats (Overstreet et al., 2002; Wills et al., 2008). In order to illustrate sensitization of anxiety-like behavior in adolescent rats it would need to be shown that neither continuous or a single cycle of ethanol produced anxiety, which was not demonstrated in previous work (Wills et al., 2008).

The current studies were performed to evaluate whether repeated withdrawals sensitize anxiety-like behavior in adolescent rats. Additionally, it was evaluated whether there were agerelated differences in the sensitivity to the effects of repeated withdrawals between adolescent and adult rats. Further experiments determined the duration (amount of time following the final withdrawal) of anxiety-like behavior in both adolescent and adult rats. In all of these studies, ethanol intake and BECs were measured to make sure behavioral effects were not dependent on differences in BECs. Finally, it was determined whether certain drug pretreatments 
(benzodiazepine receptor antagonist, $\mathrm{CRF}_{1}$ receptor antagonist, or 5- $\mathrm{HT}_{1 \mathrm{~A}}$ receptor agonist) would prevent the development of sensitized anxiety-like behavior in adolescents.

\section{MATERIALS AND METHODS}

\section{Animals}

Male Sprague Dawley rats (Charles-River, Raleigh, NC) were obtained at 7 weeks of age for the adult groups and 3 weeks of age for the adolescent groups. Animals were group housed for 1 day to adapt to the local conditions (light/dark cycle of 12:12, with lights on between 0700 and 1900 hours). Rats were then individually housed for the remainder of the experiments with food and fluids monitored as described below. The experiments described were approved by the University of North Carolina Institutional Animal Care and Use Committee.

\section{Ethanol and Control Diets}

Following a day of adaptation to isolate housing, all rats were placed on nutritionally complete liquid diets that have been used routinely in this laboratory (e.g., Frye et al., 1983; Knapp et al., 1998; Moy et al., 1997; Overstreet et al., 2002). The diet is lactalbumin/dextrose-based with vitamins, minerals, and other nutrients from Dyets (Bethlehem, PA). The number of calories from dextrose were equated with calories from the ethanol so that both control diet (CD) and ethanol diet (ED) were calorically balanced. As previously described (e.g., Overstreet et al., 2002), a modified pair-feeding design was used such that the volumes of ethanol diet consumed equaled the volume available to controls on the subsequent day. Thus, calorie intake was balanced across groups over the course of the period of diet exposure. Rats were then habituated for 3 days on $\mathrm{CD}$ and then placed into 1 of 3 treatment groups. Generally, one-third of the rats received 19 days of $\mathrm{CD}$ and the other two-thirds received ethanol diet (3.5\% or $2.5 \%$ ED). ED was administered in a continuous (CON; 15 days of continuous ED; see Fig. 1A), single cycle (CY1; 14 days of CD followed by one 5-day cycle of ED; see Fig. $1 B$ ), or repeated cycles (CY3; three 5-day cycles of ED separated by two 2-day CD exposures; see Fig. 1C). Rats were given $\mathrm{CD}$ in a volume equivalent to that consumed by the ED group on the previous day. Rats were also weighed weekly and volumes of $\mathrm{CD}$ were adjusted to minimize weight gain differences between groups. $\mathrm{ED}$ and $\mathrm{CD}$ volumes were measured daily at the end of the dark cycle to determine $\mathrm{g} / \mathrm{kg}$ intake/day. Behavioral measures were obtained at various times into the final withdrawal and will be discussed in the following sections.

\section{Social Interaction Test}

The social interaction test was first described by File and Hyde (1978) and has been used regularly in our laboratory to assess anxiety-like behavior. The results of the social interaction test have also been confirmed with the use of the elevated plus maze (Overstreet et al., 2002, $2004 \mathrm{~b})$. In the social interaction test, rats were placed into a $60 \times 60 \mathrm{~cm}$ square open field with $15 \times 15 \mathrm{~cm}$ squares marked on the floor under low lighting conditions $(30 \mathrm{~lx})$. Two rats naïve to the testing environment were paired according to body weight and monitored for 5 minutes. An observer blind to the treatment condition measured the amount of time (in seconds) that each rat was engaged in social behavior (conspecific grooming, sniffing, following, crawling over/under) with its partner. Line crosses were also recorded as a measure of locomotor activity. Ethanol withdrawal has been repeatedly shown to reduce social interaction and sometimes locomotor activity as well (Breese et al., 2004; Overstreet et al., 2002, 2003, 2004a,b). However, it is important to note that reductions in social interaction and locomotor activity seem to be independently manipulatable (Overstreet et al., 2002). Additionally, previous work illustrated that the social behavior of 1 member of a testing pair is independent of the other rat's behavior (Breese et al., 2004; Overstreet et al., 2002, 2003, 2004a). It is therefore possible to use the data from individual animals rather than the average performance of the pair (Overstreet et al., 2003). 


\section{Repeated Versus a Single Withdrawal}

These experiments determined whether anxiety-like behavior was sensitized in adolescent rats. Adult rats previously showed reduced seconds of social interaction following repeated withdrawals but not after a single 5-day cycle or continuous exposure of $4.5 \% \mathrm{ED}$ (Breese et al., 2004; Overstreet et al., 2002). In an initial experiment, it was illustrated that a single 5-day cycle of $4.5 \% \mathrm{ED}$ reduced social interaction compared to rats that received $\mathrm{CD}$. This effect of anxiety-like behavior following a single cycle of $4.5 \% \mathrm{ED}$ is most likely due to the increased ethanol intake demonstrated by adolescent rats. Therefore, additional experiments were needed with adolescent and adult rats consuming lower ethanol diet concentrations. These rats were placed into 1 of 5 groups: $\mathrm{CD}$ throughout the study (CD), 2.5\% or 3.5\% ED for three 5-day cycles interspersed with two 2-day withdrawal periods (rats received CD; $2.5 \% \mathrm{CY} 3$ or $3.5 \%$ CY3), 4 days of $\mathrm{CD}$ followed by 15 continuous days of $2.5 \% \mathrm{ED}(2.5 \% \mathrm{CON})$, or 14 days of $\mathrm{CD}$ followed by a single 5-day cycle of $2.5 \% \mathrm{ED}(2.5 \% \mathrm{CY} 1)$. All behavioral measures were performed on the 19th day of diet administration when rats maintained on ED were placed on $\mathrm{CD}$ followed by behavioral testing starting 5 hours into withdrawal when blood ethanol levels have fallen to zero (Breese et al., 2004; Overstreet et al., 2002; Wills et al., 2008). On the test day, all adolescent rats were the same age.

\section{Duration of Reduced Social Interaction Following Repeated Withdrawals}

These experiments were conducted to determine the duration of anxiety-like behavior (measured by reduction in social interaction) following repeated withdrawal in both adolescent and adult rats. Previous work in adult rats illustrated that anxiety-like behavior returns to baseline (CD values) by 48 hours following the final withdrawal in rats exposed to repeated withdrawals from 7\%ED (Overstreet et al., 2002). In these experiments adolescent rats were exposed to either repeated withdrawals from $2.5 \% \mathrm{ED}$ (as described above) or CD. Following these treatments, separate groups of rats were given social interaction tests at either 5 hours, $1,2,3,7,14$, or 18 days following the final withdrawal. At each time point a separate control group was tested to correct for any decreases in social interaction scores that might occur with age. Duration of anxiety-like behavior was also evaluated in adult rats. Adults were exposed to either repeated withdrawals from $3.5 \% \mathrm{ED}$ (this concentration provides equivalent $\mathrm{g} / \mathrm{kg}$ intake and BEC compared to $2.5 \% \mathrm{ED}$ treatment in adolescents) or CD. Separate groups of adult rats were given social interaction tests at either 5 hours, 1 day, or 2 days following the final withdrawal. All rats are maintained on $\mathrm{CD}$ from the final withdrawal until the time of testing.

\section{Blood Ethanol Concentration}

A separate group of rats were used for BEC analysis and were not included in any of the behavioral tests to prevent potential effects of multiple blood sampling on social interaction behavior. These groups showed comparable ethanol intake to the groups used in behavioral tests in most instances. When differences in ethanol intake were present, rats that were used for blood collection had slightly higher ethanol intake. BECs were taken from groups of adolescent rats that received either continuous $2.5 \% \mathrm{ED}$, a single cycle of $2.5 \% \mathrm{ED}$, or repeated cycles of $2.5 \%$ or $3.5 \% \mathrm{ED}$, in the manner described above. BECs were also collected from adult rats that received repeated cycles of $2.5 \% \mathrm{ED}$ or $3.5 \% \mathrm{ED}$. Blood was removed from the tip of the tail during the last hour of the dark cycle (0600) on first, fifth, sixth, 10th, and 11th days of ED. Additionally, on the last day of ethanol diet (15th day) blood was collected at the time of ethanol removal (hour 0 ) and then 2 and 4 hours later.

Blood samples were then analyzed with gas chromatographic methods. Tail blood $(6 \mu \mathrm{l})$ and standards ( $6 \mu \mathrm{l} ; 0$ to $200 \mathrm{mg} \%$ ) were combined with $375 \mu \mathrm{l}$ of distilled water and $0.5 \mathrm{~g} \mathrm{NaCl}$ in $12 \times 75 \mathrm{~mm}$ borosilicate glass culture tubes. These tubes were capped and then heated to $55^{\circ} \mathrm{C}$ for 10 minutes after which $1.5 \mathrm{ml}$ of head-space gas was removed from the tube and 
injected directly into an SRI $8610 \mathrm{C}$ gas chromatograph (Torrance, CA), as previously described (Breese et al., 2004; Navarro et al., 2003; Overstreet et al., 2002).

\section{Drug Testing}

The following experiments were conducted to determine the effects of specific neural systems in the sensitization that occurs in adolescent rats during repeated ethanol withdrawals. A $\mathrm{CRF}_{1}$-receptor antagonist (CP-154,525; $10 \mathrm{mg} / \mathrm{kg}$; Pfizer Inc., Groton, CT), a benzodiazepine receptor antagonist (flumazenil; $5 \mathrm{mg} / \mathrm{kg}$; Roche, Basel, Switzerland), or a $5-\mathrm{HT}_{1 \mathrm{~A}}$-receptor agonist (buspirone; $0.6 \mathrm{mg} / \mathrm{kg}$; RBI-Sigma, St. Louis, MO) was administered 4 hours following the removal of ethanol diet during each of the initial 2 cycles (see Fig. 1C). CP-154,526 and flumazenil were prepared as microfine suspensions in $0.5 \%$ carboxy-methylcellulose, while buspirone was dissolved in $0.9 \%$ saline. All drugs were injected at a volume of $2 \mathrm{ml} / \mathrm{kg}$. These drug doses were chosen based on previous studies in adults that illustrated the effectiveness of these drugs to block the sensitization of anxiety-like behavior following repeated withdrawals (Breese et al., 2005b;Overstreet et al., 2003,2004a,b). Importantly, the drugs were not administered during the final (third) withdrawal, thus animals were tested for anxiety in a drug free state. This important feature of the design permits assessments of drug effects on the sensitization or maladaptation that develops over repeated withdrawals, rather than on the acute behavioral manifestation of withdrawal. Animals that were not injected with drugs (CD-Veh and ED-Veh) were injected with $0.5 \%$ carboxy-methylcellulose to control for effects of vehicle.

\section{Statistics}

Analyses of social interaction, locomotor activity, ethanol intake, and BECs were conducted with one-way ANOVAs. Comparisons of BECs between adolescent and adult rats were analyzed with a repeated measures ANOVA. Differences between individual groups were determined with Fisher's PLSD post-hoc tests.

\section{RESULTS}

\section{Sensitization of Anxiety-Like Behavior From Repeated Withdrawals in Adolescent Rats}

Previous work demonstrated that repeated withdrawals from 4.5\%ED reduced social interaction in adolescents (Wills et al., 2008). However, it was unclear whether a sensitization of anxiety-like behavior from repeated withdrawals occurred in adolescent rats as it was shown to do in adults. Analysis of social interaction in adolescent rats given lower ethanol concentrations revealed a main effect of diet treatment $[F(3,28)=6.57, p<0.005 ;$ Fig. $2 A]$. It was demonstrated that adolescent rats given repeated withdrawals from $2.5 \% \mathrm{ED}$ (CY3) had lower social interaction compared to rats given $\mathrm{CD}$, continuous $2.5 \% \mathrm{ED}(\mathrm{CON})$, or a single cycle of $2.5 \% \mathrm{ED}(\mathrm{CY} 1)$. There was no significant difference among groups in locomotor activity $[F(3,28)=0.32$, N.S.; Fig. $2 B]$.

\section{Ethanol Intake in Adolescent Rats}

Ethanol intake was compared among adolescent rats that received either continuous ethanol (Con), repeated withdrawals (CY3), or a single cycle (CY1) of 2.5\%ED. Ethanol intake was averaged across cycles (average of daily intake for days 1 to $5=$ cycle 1 , days 6 to $10=$ cycle 2 , and days 11 to $15=$ cycle 3 ) for each group. During cycle 1 , there was a significant effect of group on ethanol intake $[F(1,14)=25.38, p<0.0005$; Table 1]. Adolescents that received continuous ethanol diet displayed higher ethanol intake compared to those in the repeated withdrawal group. The single cycle group was left out of the comparisons between cycles 1 and 2 because these rats were receiving $\mathrm{CD}$ during this period. Additionally, during the second cycle there was a significant difference between ethanol treatment groups $[F(1,14)=12.68$, $p<0.005]$, with continuous exposed rats still having higher ethanol intake than rats given 
repeated withdrawals. During the third cycle, there was also a significant effect of ethanol treatment $[F(2,21)=4.27, p<0.05]$. During this cycle, the single ethanol cycle group had the highest intake and was significantly higher than the repeated withdrawal rats but not the continuously exposed rats. Continuously exposed rats and those given repeated withdrawals were not different during this cycle.

\section{Blood Ethanol Concentrations in Adolescent Rats}

BECs were analyzed among groups of adolescent rats given 3 cycles of $2.5 \% \mathrm{ED}$ (CY3; repeated withdrawal paradigm), 15 days of continuous $2.5 \% \mathrm{ED}$ (Con), or a single 5-day cycle of $2.5 \% \mathrm{ED}$ (CY1). Repeated measures ANOVA revealed no significant effect of group (diet treatment) either during the first 2 weeks of treatment $[F(1,42)=2.26$, NS; Table 2] or during the final week $[F(2,63)=0.49$, NS; Table 2].

\section{Anxiety-Like Behavior From Lower Ethanol Diet Concentrations in Adult Rats}

The next set of experiments determined whether adult rats given these lower ethanol concentrations also demonstrated anxiety-like behavior. In these studies, there was a main effect of ethanol treatment $[F(2,23)=6.87, p<0.005$; Fig. $3 A]$. Adult rats given repeated withdrawals from either $2.5 \%$ or $3.5 \%$ ED showed a reduction in social interaction compared to rats given $\mathrm{CD}$. Additionally, a main effect of treatment was found for locomotor activity $[F(2,23)=4.08, p<0.05$; Fig. $3 B]$ in these adult rats. Rats given repeated withdrawals from $3.5 \% \mathrm{ED}$ had lower activity than rats given $\mathrm{CD}$. There were no differences in locomotor activity between $\mathrm{CD}$ and $2.5 \% \mathrm{ED}$ or $2.5 \% \mathrm{ED}$ and $3.5 \% \mathrm{ED}$ rats.

\section{Comparison of Ethanol Intake Between Adolescent and Adult Rats}

Further experiments were aimed at directly comparing behavioral differences between adolescent and adult rats. It was therefore necessary to determine what ethanol concentration would be able to produce comparable ethanol intake between adolescent and adult rats. Previous work with ethanol diets illustrated that adolescent rats given the same ethanol diet concentration as adults will have higher $\mathrm{g} / \mathrm{kg}$ intake (Wills et al., 2008). A simplistic way to compare adolescents and adults is to evaluate ethanol intake by cycles. During cycle 1 there were significant differences among $2.5 \%$ and $3.5 \% \mathrm{ED}$ treated adults and adolescents $[F(2,25)$ $=76.10, p<0.0001$; Table 3]. Adolescents treated with 2.5\%ED drank more than adults who received the same ethanol treatment. Additionally, adults treated with 3.5\%ED drank more than adults given $2.5 \% \mathrm{ED}$. Finally, adolescents treated with $2.5 \% \mathrm{ED}$ consumed more ethanol than adults who received 3.5\%ED.

Averages of ethanol intake during cycle 2 were also different among groups of $2.5 \%$ and $3.5 \%$ ED-treated adults and adolescents $[F(2,25)=80.46, p<0.0001$; Table 3]. Again, adolescents treated with $2.5 \%$ ED drank more than adults who received the same ethanol treatment. Additionally, adult rats treated with 3.5\%ED showed higher consumption than those given $2.5 \%$ ED. Similar to cycle 1, adolescents treated with $2.5 \%$ ED consumed more ethanol than adults who received $3.5 \% \mathrm{ED}$.

In the third cycle, group differences were also demonstrated among $2.5 \%$ and $3.5 \%$ treated adults and adolescents $[F(2,25)=68.41, p<0.0001$; Table 3]. Adolescents treated with 2.5\% ED drank more than adults who received the same ethanol treatment. Adult rats treated with $3.5 \% \mathrm{ED}$ showed higher consumption than rats given $2.5 \% \mathrm{ED}$. Importantly, during this last cycle adolescents given 2.5\%ED and adults given 3.5\% ED were not different in their ethanol intake. 


\section{Comparison of Blood Ethanol Concentrations Between Adolescent and Adult Rats}

BECs were analyzed between adolescent rats treated with $2.5 \% \mathrm{ED}$ and adults given either $2.5 \%$ or $3.5 \%$ ED. Repeated measures ANOVA revealed a significant effect of group (Adolescent $2.5 \% \mathrm{ED}$, Adult $2.5 \% \mathrm{ED}$ and $3.5 \% \mathrm{ED}$ ) across the days examined $[F(2,147)=$ $14.64, p<0.0001$; Table 4]. Additionally, a separate repeated measures ANOVA between $2.5 \%$ ED treated adolescent and adult rats showed there was no significant effect of group $[F(1,98)$ $=0.63$, NS; Table 4]. However, a repeated measures ANOVA between 2.5\%ED treated adolescent and $3.5 \%$ ED treated adult rats exposed a significant difference between these groups $[F(1,98)=14.34, p<0.005$; Table 4] with adult rats receiving $3.5 \%$ ED having slightly higher BECs. BECs in both adolescents and adults returned to $0 \mathrm{mg} \% 6$ hours into withdrawal on the final test day (day 15, data not shown).

\section{Duration of Anxiety-Like Behavior From Repeated Withdrawals}

Further experiments determined the duration of anxiety-like behavior (measured at various times after the final withdrawal) in adolescent and adult rats following repeated withdrawals. In adult rats exposed to repeated withdrawals from $3.5 \% \mathrm{ED}$, there was a significant difference in social interaction between groups tested at different durations $[F(3,36)=6.60, p<0.005$;

Fig. 4]. Adults rats tested 5 hours into the final withdrawal showed reduced social interaction compared to CD-treated rats (as shown previously above). However, adult rats tested 24 and 48 hours into the final withdrawal were different from rats tested at 5 hours but not from CDtreated rats. These same experiments were performed in adolescent rats exposed to repeated withdrawals from $2.5 \% \mathrm{ED}$. These data are presented as a percent of control to account for the decrease in social interaction that occurs with age. In adolescent rats, there was a significant difference in social interaction between groups tested at different durations $[F(7,80)=9.02$, $p<0.0001$; Fig. 5]. Groups tested 5 hours, 1, 2, 3, and 7 days into the final withdrawal showed significantly reduced social interaction (\% of control values) compared to control groups. However, groups tested 14 and 18 days into the final withdrawal were not different from controls.

\section{Effects of Selective Drugs on the Sensitization of Anxiety-Like Behavior Following Repeated Withdrawals in Adolescent Rats}

The final sets of experiments were performed to determine whether a $\mathrm{CRF}_{1}$ antagonist (CP-154,526), a benzodiazepine receptor antagonist (flumazenil), or a 5-HT $1 \mathrm{~A}^{\text {-receptor }}$ agonist (buspirone) would block the sensitization of anxiety-like behavior following repeated withdrawal in adolescent rats, as it has been shown to do in adult rats (Knapp et al., 2004; Overstreet et al., 2003). In adolescent rats, there was a significant difference between drug treatments in social interaction $[F(4,97)=2.58, p<0.05$; Fig. $6 A]$. Adolescent rats given buspirone, flumazenil, or CP-154,526 had social interaction scores not different from those of CD-treated rats. Additionally, adolescent rats injected with vehicle showed reduced social interaction compared to all drug treated groups. Locomotor activity was also evaluated in the social interaction test following these drug treatments and no significant differences among treatment groups were found $[F(4,97)=0.828$, NS; Fig. $6 B]$.

\section{DISCUSSION}

Adolescent rats exhibited sensitized anxiety-like behavior following repeated withdrawals, which has been previously demonstrated with 4.5\%ED in adults (Overstreet et al., 2002). This effect was illustrated by a reduction in social interaction (a validated measure of anxiety-like behavior; File and Seth, 2003) in adolescent rats that experienced repeated withdrawals from $2.5 \%$ ED. Importantly, adolescents given either a single 5-day cycle or continuous 15 days of $2.5 \% \mathrm{ED}$ (same ethanol exposure as repeated withdrawal groups) did not exhibit this reduction in social interaction. These data, therefore, indicate that the production of anxiety-like behavior 
(with this ED concentration) was dependent on the cycled nature of the ethanol exposure. Additionally, these studies illustrated that locomotor activity was not reduced by any of these ethanol treatments in adolescent rats. Previous research from our laboratory demonstrated that adolescent rats given repeated withdrawals from higher ED concentrations can exhibit anxietylike behavior following repeated withdrawals (Wills et al., 2008). These experiments, however, are the first to demonstrate that a sensitization of this anxiety-like behavior can occur in adolescent rats. Previous acute ethanol withdrawal tests in adolescent rats showed reduced or no anxiety-like response at this age compared to adult rats (Doremus et al., 2003; Varlinskaya and Spear, 2004). Therefore, the presence of this anxiety-like phenotype after repeated ethanol withdrawals in adolescent rats establishes that the cycled nature of ethanol exposure and age of testing are critical to producing anxiety-like behavior during ethanol withdrawal.

Earlier work in adult rats illustrated that they too can undergo sensitization of anxiety-like behavior (e.g., Overstreet et al., 2002). These studies used somewhat higher ED concentration (4.5\%ED), so it was unknown whether these lower ED concentrations $(2.5 \% \& 3.5 \% \mathrm{ED})$ would also produce anxiety-like behavior in adult rats. The results established that indeed repeated withdrawals from these lower ED concentrations produced anxiety-like behavior in adult rats. These data indicated that although adolescent rats demonstrate sensitized anxiety-like behavior, that this response was not unique from the behavioral response of adult rats at these lower ethanol diet concentrations. It is notable that although we report here that rats receive two formal extended withdrawals periods of 48 hours, it is reasonable to assume that the rats may also occasionally experience a type of brief withdrawal between meals across the circadian cycle (e.g., during sleep bouts). Despite the possibility of these mini-withdrawals, previous research shows that the formal withdrawals capture the essence of the sensitization process as continuous ethanol exposure or a single 5-day cycle (with both types of groups conceivably experiencing occasional mini-withdrawals) do not lead to substantial anxiety relative to nonethanol-exposed rats (e.g., Overstreet et al., 2002).

Analysis of ethanol intakes and BECs illustrated that differences in behavior among adolescent groups (CY1, Con, and CY3) were not related to differences in ethanol intake and BECs. Additionally, a comparison between the ethanol intake of adolescent and adult rats revealed adolescents consumed more $\mathrm{g} / \mathrm{kg}$ of ethanol than adults given the same treatment. This increased ethanol intake in adolescent rats has been previously demonstrated in our laboratory with liquid diet (Wills et al., 2008), as well as in other laboratories with other ethanol administration paradigms (Bell et al., 2006; Doremus et al., 2005; Rodd-Henricks et al., 2002a,b; Vetter et al., 2007; Walker et al., 2008). Furthermore, these data illustrated that adolescent rats given $2.5 \% \mathrm{ED}$ had comparable ethanol intake to adults given 3.5\%ED. BEC comparisons between these 2 groups show that even with comparable ethanol intake, adult rats treated with 3.5\%ED had a slightly higher BEC than 2.5\%ED treated adolescent rats. Since both of these groups showed the most comparable ethanol intake and BEC, they were used for comparisons in duration experiments. It is worth noting also that BECs in both adolescent and adult rats may represent the BEC on the falling end of the curve and therefore may be slightly lower than peak BEC on a given day.

In adolescent rats, it was demonstrated that anxiety-like behavior was present up to 1 week following repeated ethanol withdrawals. This effect is in stark contrast to the effect in adult rats where anxiety-like behavior returns to baseline after only 24 hours. These data illustrate that the anxiety-like behavior produced from repeated withdrawals is much longer lasting in adolescent versus adult rats. Therefore, it appears that adolescent rats may be more vulnerable to the effects of repeated withdrawals on this measure. The relative importance of this finding to adolescent versus adult risk for further alcohol abuse/relapse is unknown. While the specific consequences of this extended duration of anxiety-like behavior are unknown, previous research supports this idea that adolescent ethanol exposure can affect future responses to 
ethanol in adulthood. A body of evidence shows that the differential sensitivities to ethanol displayed by adolescents can also be maintained into adulthood (Slawecki, 2002; White et al., 2000, 2002). Additionally, Crews and colleagues (2000) showed that a 4-day binge ethanol exposure in adolescents caused brain damage in select regions that does not appear in adults. Further, in P rats it was illustrated that prior ethanol exposure during adolescence, but not in adulthood, affects later ethanol responding. That is, adolescent exposure in P rats led to faster responses to ethanol, less resistance to extinction, and increased responding to ethanol upon re-exposure (Rodd-Henricks et al., 2002a,b). This evidence indicates ethanol treatment during the adolescent period can affect future responses to ethanol. These observations of long lasting effects in rodents may relate to clinical evidence demonstrating that alcohol use during adolescence is the largest predictor for future alcoholism (Grant, 1998).

Finally, it was illustrated that this increased anxiety-like behavior produced from repeated withdrawals could be blocked by pretreatment with buspirone, flumazenil, or CP-154,526. Notably, these drugs blocked sensitization of this anxiety-like behavior since no drugs were administered during the final withdrawal when rats were tested for anxiety-like behavior. Previous work in adults has also shown that pretreatment with these drugs also blocked anxietylike behavior (Breese et al., 2005b; Overstreet et al., 2003, 2004a,b). The effectiveness of these drugs in both age groups indicates that mechanisms that are responsible for this anxiety-like behavior are likely similar between adolescent and adult rats. These findings suggest that at least some future pharmacological treatment strategies in alcoholism might apply broadly across age.

In summary, these experiments illustrated that adolescent rats exhibit sensitized anxiety-like behavior that had been previously demonstrated in adult rats (Overstreet et al., 2002).

Comparisons of adolescent and adult rats at these lower ethanol diet concentrations revealed that the sensitivity of this response seemed to be similar for both ages. However, the duration of this anxiety-like response was found to be much longer in adolescent rats that experienced repeated withdrawals compared to their adult counterparts. On the other hand, it was illustrated that drugs known to be effective in preventing the sensitization of anxiety-like behavior in adult rats are also effective in adolescents. Future work will further explore the mechanisms that might be responsible for the extended duration of anxiety-like behavior in adolescent rats.

\section{Acknowledgments}

These studies were supported by AA11605, AA14284, and NRSA Predoctoral Fellowship AA16704. We wish to thank Pfizer (Groton, CN) for CP-154,526. We thank Robert Angel and Kui-Ling Huang for technical assistance.

\section{REFERENCES}

Acheson SK, Richardson R, Swartzwelder HS. Developmental changes in seizure susceptibility during ethanol withdrawal. Alcohol 1999;18:23-26. [PubMed: 10386661]

Ballenger JC, Post RM. Kindling as a model for alcohol withdrawal syndromes. Br J Psychiatry 1978;133:1-14. [PubMed: 352467]

Becker HC, Hale RL. Repeated episodes of ethanol withdrawal potentiate the severity of subsequent withdrawal seizures: an animal model of alcohol withdrawal "kindling.". Alcohol Clin Exp Res 1993;17:94-98. [PubMed: 8452212]

Bell RL, Rodd ZA, Sable HJ, Schultz JA, Hsu CC, Lumeng L, Murphy JM, McBride WJ. Daily patterns of ethanol drinking in peri-adolescent and adult alcohol-preferring $(\mathrm{P})$ rats. Pharmacol Biochem Behav 2006;83:35-46. [PubMed: 16442608]

Breese GR, Knapp DJ, Overstreet DH. Stress sensitization of ethanol withdrawal-induced reduction in social interaction: inhibition by CRF-1 and benzodiazepine receptor antagonists and a 5-HT1Areceptor agonist. Neuropsychopharmacology 2004;29:470-482. [PubMed: 12955093] 
Breese GR, Overstreet DH, Knapp DJ. Conceptual framework for the etiology of alcoholism: a "kindling"/stress hypothesis. Psychopharmacology (Berl) 2005a;178:367-380. [PubMed: 15765253]

Breese GR, Overstreet DH, Knapp DJ, Navarro M. Prior multiple ethanol withdrawals enhance stressinduced anxiety-like behavior: inhibition by CRF1- and benzodiazepine-receptor antagonists and a 5HT1a-receptor agonist. Neuropsychopharmacology 2005b;30:1662-1669. [PubMed: 15726114]

Clark DB, Kirisci L, Tarter RE. Adolescent versus adult onset and the development of substance use disorders in males. Drug Alcohol Depend 1998;49:115-121. [PubMed: 9543648]

Crews FT, Braun CJ, Hoplight B, Switzer RC III, Knapp DJ. Binge ethanol consumption causes differential brain damage in young adolescent rats compared with adult rats. Alcohol Clin Exp Res 2000;24:1712-1723. [PubMed: 11104119]

Doremus TL, Brunell SC, Rajendran P, Spear LP. Factors influencing elevated ethanol consumption in adolescent relative to adult rats. Alcohol Clin Exp Res 2005;29:1796-1808. [PubMed: 16269909]

Doremus TL, Brunell SC, Varlinskaya EI, Spear LP. Anxiogenic effects during withdrawal from acute ethanol in adolescent and adult rats. Pharmacol Biochem Behav 2003;75:411-418. [PubMed: 12873633]

File SE, Hyde JR. Can social interaction be used to measure anxiety? Br J Pharmacol 1978;62:19-24. [PubMed: 563752]

File SE, Seth P. A review of 25 years of the social interaction test. Eur J Pharmacol 2003;463:35-53. [PubMed: 12600701]

Frye GD, McCown TJ, Breese GR. Characterization of susceptibility to audiogenic seizures in ethanoldependent rats after microinjection of gamma-aminobutyric acid (GABA) agonists into the inferior colliculus, substantia nigra or medial septum. J Pharmacol Exp Ther 1983;227:663-670. [PubMed: 6317842]

Grant BF. The impact of a family history of alcoholism on the relationship between age of onset of alcohol use and DSM-IV alcohol dependence: results of the National Longitudinal Alcohol Epidemiological Survey. Alcohol Health Res World 1998;22:144-147. [PubMed: 15706789]

Hiller-Sturmhöfel S, Swartzwelder HS. Alcohol's effects on the adolescent brain: what can be learned from animal models. Alcohol Res Health 20042005;28:213-221.

Johnston, LD.; O'Malley, PM.; Bachman, JG.; Schulenberg, JE. National Institute on Drug Abuse. Bethesda, MD; 2007. Monitoring the Future National Results on Adolescent Drug Use: Overview of Key Findings, 2006 (NIH Publication No. 07-6202); p. 71

Knapp DJ, Duncan GE, Crews FT, Breese GR. Induction of Fos-like proteins and ultrasonic vocalizations during ethanol withdrawal: further evidence for withdrawal-induced anxiety. Alcohol Clin Exp Res 1998;22:481-493. [PubMed: 9581657]

Knapp DJ, Overstreet DH, Moy SS, Breese GR. SB242084, flumazenil, and CRA1000 block ethanol withdrawal-induced anxiety in rats. Alcohol 2004;32:101-111. [PubMed: 15163561]

Kokka N, Sapp DW, Taylor AM, Olsen RW. The kindling model of alcohol dependence: similar persistent reduction in seizure threshold to pentylenetetrazol in animals receiving chronic ethanol or chronic pentylenetetrazol. Alcohol Clin Exp Res 1993;17:525-531. [PubMed: 8392817]

McCown TJ, Breese GR. Multiple withdrawals from chronic ethanol "kindles" inferior collicular seizure activity: evidence for kindling of seizures associated with alcoholism. Alcohol Clin Exp Res 1990;14:394-399. [PubMed: 2378423]

Moy SS, Knapp DJ, Criswell HE, Breese GR. Flumazenil blockade of anxiety following ethanol withdrawal in rats. Psychopharmacology (Berl) 1997;131:354-360. [PubMed: 9226737]

Navarro M, Cubero I, Knapp DJ, Thiele TE. MTII-induced reduction of voluntary ethanol drinking is blocked by pretreatment with AgRP-(83-132). Neuropeptides 2003;37:338-344. [PubMed: 14698676]

Overstreet DH, Knapp DJ, Breese GR. Accentuated decrease in social interaction in rats subjected to repeated ethanol withdrawals. Alcohol Clin Exp Res 2002;26:1259-1268. [PubMed: 12198403]

Overstreet DH, Knapp DJ, Breese GR. Modulation of multiple ethanol withdrawal-induced anxiety-like behavior by CRF and CRF1 receptors. Pharmacol Biochem Behav 2004a;77:405-413. [PubMed: 14751471] 
Overstreet DH, Knapp DJ, Breese GR. Similar anxiety-like responses in male and female rats exposed to repeated withdrawals from ethanol. Pharmacol Biochem Behav 2004b;78:459-464. [PubMed: $15251254]$

Overstreet DH, Knapp DJ, Moy SS, Breese GR. A 5-HT1A agonist and a 5-HT2c antagonist reduce social interaction deficit induced by multiple ethanol withdrawals in rats. Psychopharmacology (Berl) 2003;167:344-352. [PubMed: 12677355]

Rodd-Henricks ZA, Bell RL, Kuc KA, Murphy JM, McBride WJ, Lumeng L, Li TK. Effects of ethanol exposure on subsequent acquisition and extinction of ethanol self-administration and expression of alcohol-seeking behavior in adult alcohol-preferring (P) rats: II. Adult exposure. Alcohol Clin Exp Res 2002a;26:1642-1652. [PubMed: 12436052]

Rodd-Henricks ZA, Bell RL, Kuc KA, Murphy JM, McBride WJ, Lumeng L, Li TK. Effects of ethanol exposure on subsequent acquisition and extinction of ethanol self-administration and expression of alcohol-seeking behavior in adult alcohol-preferring (P) rats: I. Periadolescent exposure. Alcohol Clin Exp Res 2002b;26:1632-1641. [PubMed: 12436051]

Slawecki CJ. Altered EEG responses to ethanol in adult rats exposed to ethanol during adolescence. Alcohol Clin Exp Res 2002;26:246-254. [PubMed: 11964565]

Varlinskaya EI, Spear LP. Acute ethanol withdrawal (hangover) and social behavior in adolescent and adult male and female Sprague-Dawley rats. Alcohol Clin Exp Res 2004;28:40-50. [PubMed: 14745301]

Vetter CS, Doremus-Fitzwater TL, Spear LP. Time course of elevated ethanol intake in adolescent relative to adult rats under continuous, voluntary-access conditions. Alcohol Clin Exp Res 2007;31:11591168. [PubMed: 17511750]

Walker BM, Walker JL, Ehlers CL. Dissociable effects of ethanol consumption during the light and dark phase in adolescent and adult Wistar rats. Alcohol 2008;42:83-89. [PubMed: 18358986]

White AM, Bae JG, Truesdale MC, Ahmad S, Wilson WA, Swartzwelder HS. Chronic-intermittent ethanol exposure during adolescence prevents normal developmental changes in sensitivity to ethanol-induced motor impairments. Alcohol Clin Exp Res 2002;26:960-968. [PubMed: 12170104]

White AM, Ghia AJ, Levin ED, Swartzwelder HS. Binge pattern ethanol exposure in adolescent and adult rats: differential impact on subsequent responsiveness to ethanol. Alcohol Clin Exp Res 2000;24:1251-1256. [PubMed: 10968665]

Wills TA, Knapp DJ, Overstreet DH, Breese GR. Differential dietary ethanol intake and blood ethanol levels in adolescent and adult rats: effects on anxiety-like behavior and seizure thresholds. Alcohol Clin Exp Res 2008;32:1350-1360. [PubMed: 18540921] 
(A) Continuous Ethanol (CON) Paradigm:

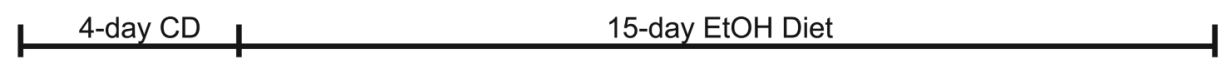

(B) Single Cycle Ethanol (CY1) Paradigm:

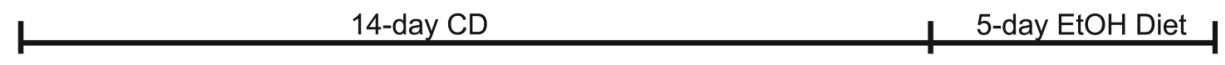

(C) Repeated Withdrawal (CY3) \& Drug Pretreatment Paradigm:

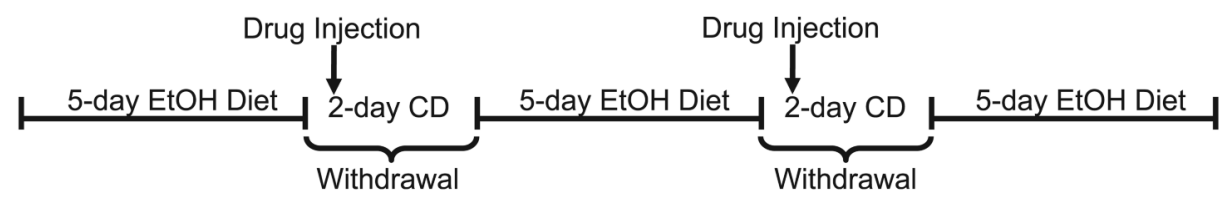

Fig. 1.

Procedure for diet administrations. (A) Continuous ethanol paradigm (Con): rats were given 4 days of control diet (CD) followed by 15 days of ethanol diet (ED). (B) Single cycle ethanol paradigm (CY1): rats were given 14 days of CD followed by one 5-day cycle of ED. (C) Repeated withdrawal (CY3) and drug pretreatment paradigm: rats were given three 5-day cycles of ED interspersed with two 2-day withdrawal periods, during which time rats receive CD. Some rats were injected with either CP-154,516, flumazenil, or buspirone 4 hours into the first 2 withdrawal periods. 

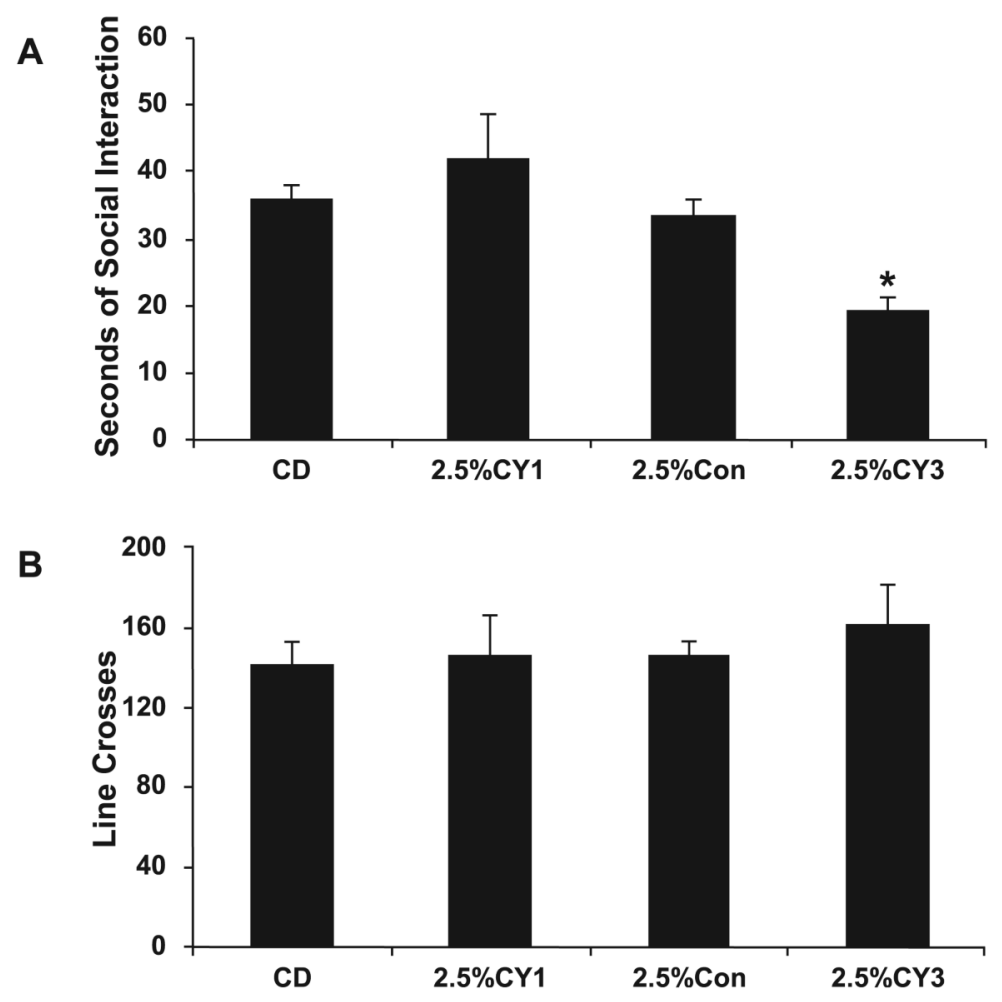

Fig. 2.

Social interaction and locomotor activity in adolescent rats (Panels $\mathbf{A}$ and $\mathbf{B}$ ). Male adolescent rats were given either control diet (CD), continuous 15 days of $2.5 \%$ ethanol diet (ED; $2.5 \%$ Con), one 5-day cycle of $2.5 \% \mathrm{ED}(2.5 \% \mathrm{CY} 1)$, or repeated ethanol withdrawals from $2.5 \% \mathrm{ED}$ (CY3). Repeated withdrawal groups were exposed to three 5-day cycles of ED interspersed with two 2-day withdrawal periods, during which rats receive $\mathrm{CD}$. All adolescent rats were tested 5 hours after removal of ethanol during the final withdrawal. Data represent means \pm SEM for 8 rats/group. * $p<0.05$ compared to CD, $2.5 \% \mathrm{CY} 1$, and $2.5 \% \mathrm{Con}$. 

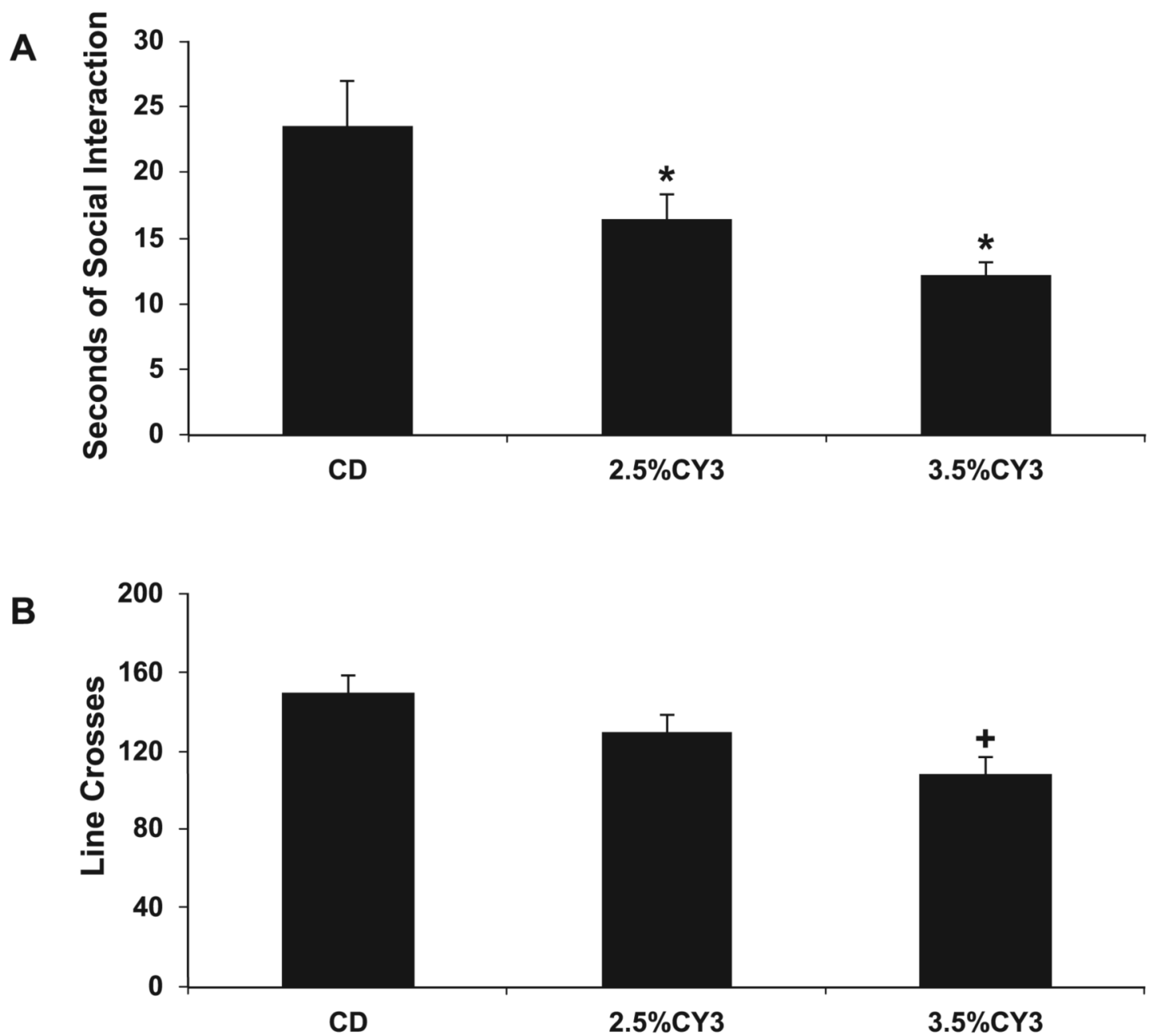

Fig. 3.

Social interaction and locomotor activity in adult rats given repeated ethanol withdrawals from lower ethanol diet concentrations (Panels A and B). Male adult rats were given control diet (CD), 2.5\% ethanol diet (ED), or 3.5\%ED. ED groups were exposed to three 5-day cycles of ED interspersed with two 2-day withdrawal periods (CY3), during which rats receive CD. Rats were tested 5 hours after removal of ethanol during the final withdrawal. Data represent means \pm SEM for 8 rats/group. ${ }^{*} p<0.05$ compared to CD in social interaction. ${ }^{+} p<0.05$ compared to $\mathrm{CD}$ in locomotor activity. 


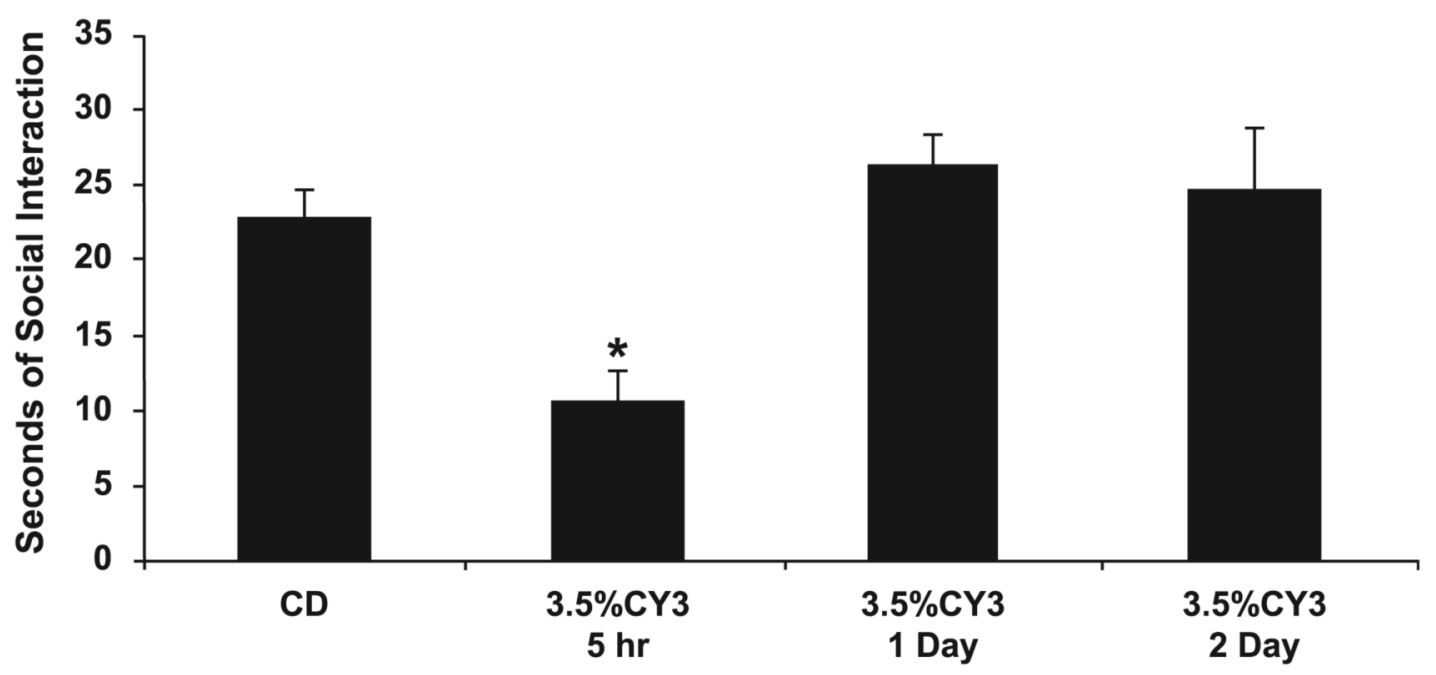

Fig. 4.

Duration of anxiety-like behavior in adult rats exposed to repeated ethanol withdrawals. Male adult rats were given either control diet (CD) or 3.5\% ethanol diet (ED) for three 5-day cycles interspersed with two 2-day withdrawals (CY3). Rats were tested 5 hours, 1 day, or 2 days after the removal of ethanol during the final withdrawal. Data represent means \pm SEM for 8 rats/group. ${ }^{*} p<0.05$ compared to all other groups. 


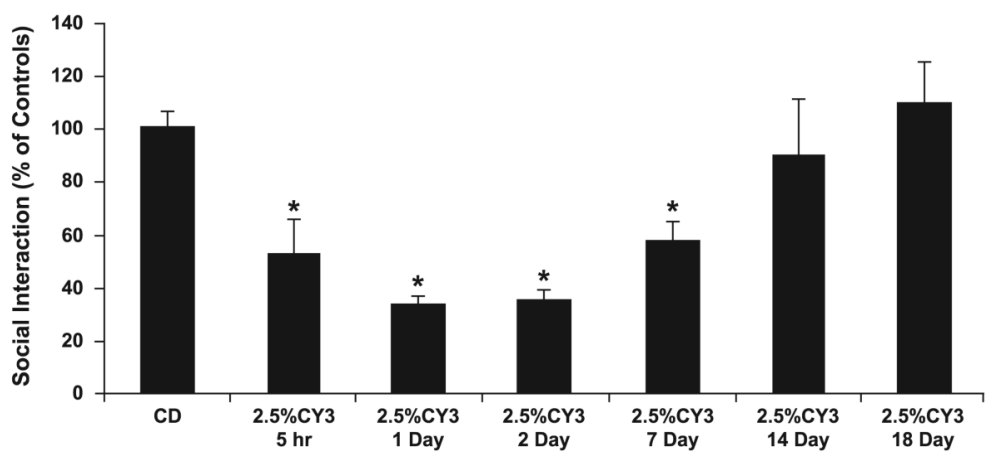

Fig. 5.

Duration of anxiety-like behavior in adolescent rats exposed to repeated ethanol withdrawals. Male adolescent rats were given either control diet (CD) or $2.5 \%$ ethanol diet (ED) for three 5-day cycles interspersed with two 2-day withdrawals (CY3). Rats were tested 5 hours, 1, 2, 7,14 , or 18 days after the removal of ethanol during the final withdrawal. Data represent mean \pm SEM for 7 to 10 rats/group. ${ }^{*} p<0.05$ compared to CD, 14 and 18 days. 

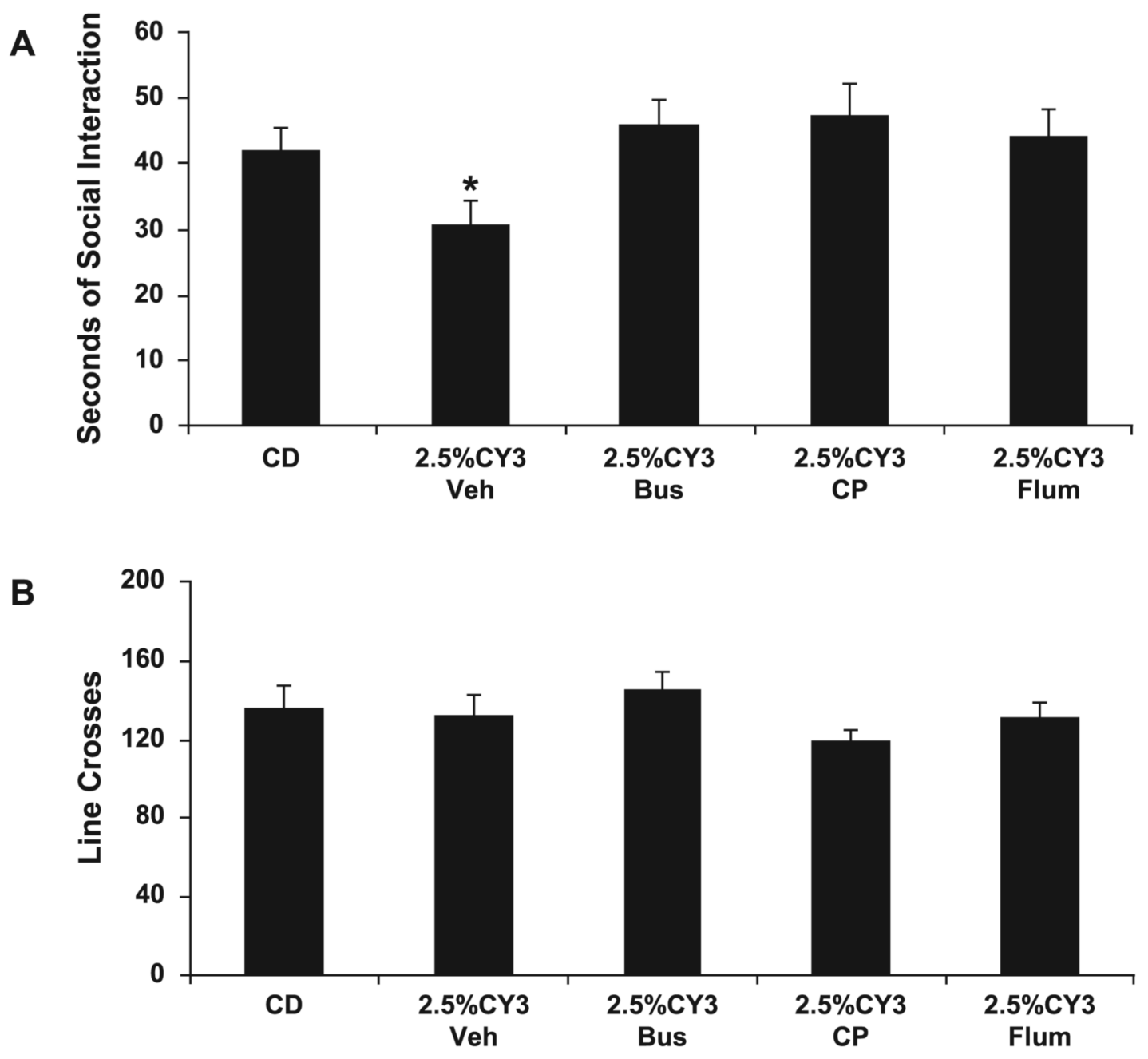

Fig. 6.

Effect of drug pretreatments on social interaction reductions caused by repeated withdrawals in adolescent rats. The $5-\mathrm{HT}_{1 \mathrm{~A}}$ receptor agonist, buspirone (Bus; $0.6 \mathrm{mg} / \mathrm{kg}$ ), benzodiazepine antagonist, flumazenil (Flum; $5 \mathrm{mg} / \mathrm{kg}$ ), $\mathrm{CRF}_{1}$ receptor antagonist, $\mathrm{CP}-154,526$ (CP; $10 \mathrm{mg} /$ $\mathrm{kg}$ ), or vehicle was given during the first 2 early withdrawals of adolescent rats given repeated ethanol withdrawals from $2.5 \%$ ethanol diet (ED; CY3). CD rats received nonalcohol control liquid diet throughout. Rats were tested 5 hours after the removal of ethanol during the final withdrawal. Data represent means \pm SEM for 16 to 25 rats/group. $* p<0.05$ comparedtoall other groups. 


\section{Table 1}

Ethanol Intake (averaged by cycles) in Adolescent Rats

\begin{tabular}{lccl}
\hline & Cycle 1 & Cycle 2 & Cycle 3 \\
\hline $2.5 \%$ CY1 & - & - & $7.16 \pm 0.1^{b}$ \\
$2.5 \%$ Con & $11.34 \pm 0.5^{a}$ & $8.62 \pm 0.2^{a}$ & $6.83 \pm 0.1$ \\
$2.5 \%$ CY3 & $8.49 \pm 0.3$ & $7.70 \pm 0.2$ & $6.66 \pm 0.1$ \\
\hline
\end{tabular}

Adolescent rats were exposed to $2.5 \%$ ethanol diet for either one 5-day cycle of ethanol diet (CY1), 15 continuous days of ethanol diet (Con), or three 5-day cycles of ethanol diet interspersed with two 2-day withdrawals (CY3). Data are an averaged daily intake for each 5-day cycle and represent mean $\mathrm{g} / \mathrm{kg} \pm \mathrm{SEM}$ for 8 rats/group.

$a_{p}<0.05$ compared to $2.5 \% \mathrm{CY} 3$ in cycles 1 and 2 .

$b_{p}<0.05$ compared to $2.5 \% \mathrm{CY} 3$ in cycle 3 . 


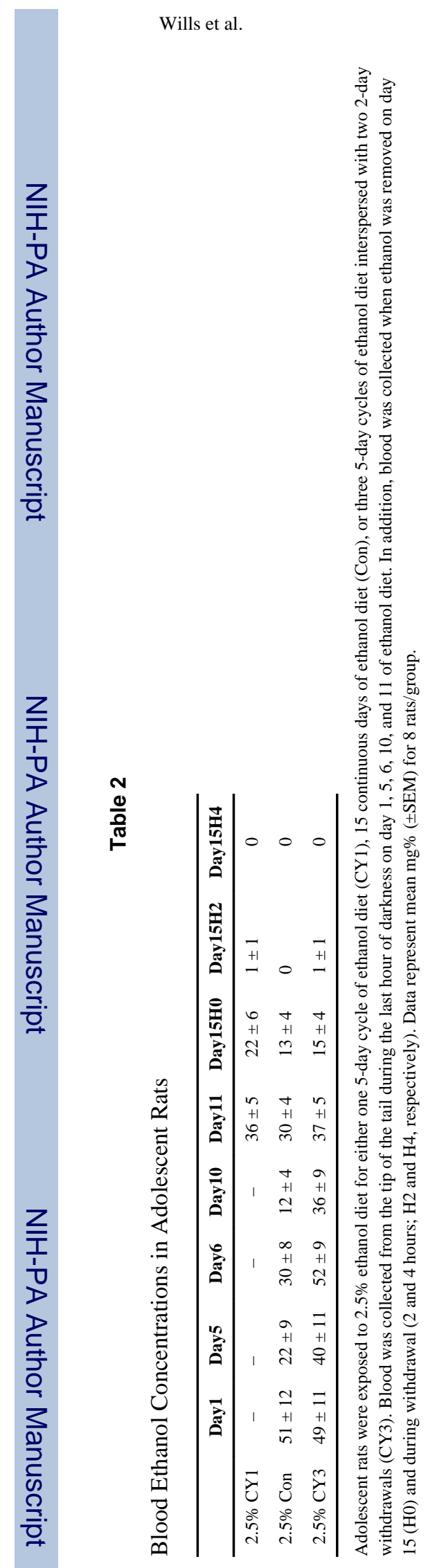

Alcohol Clin Exp Res. Author manuscript; available in PMC 2010 March 30. 
Table 3

Comparison of Ethanol Intake (averaged by cycles) Between Adolescent and Adult Rats

\begin{tabular}{llll}
\hline & Cycle 1 & Cycle 2 & Cycle 3 \\
\hline Adolescent 2.5\% CY3 & $8.49 \pm 0.3^{a}$ & $7.70 \pm 0.2^{a}$ & $6.66 \pm 0.1$ \\
Adult 2.5\% CY3 & $5.26 \pm 0.1$ & $5.13 \pm 0.1$ & $4.80 \pm 0.1^{c}$ \\
Adult 3.5\% CY3 & $7.21 \pm 0.2^{b}$ & $7.00 \pm 0.2^{b}$ & $6.88 \pm 0.2$ \\
\hline
\end{tabular}

Ethanol intake averaged by cycles for male adult and adolescent rats. 2.5\% and 3.5\% ethanol diet (ED) groups were exposed to three 5-day cycles of ED interspersed with two 2-day withdrawal periods, during which rats received control diet (CD). These data are an average of daily intake for each 5-day cycle. Data represent means \pm SEM for 8 rats/group.

$a_{p}<0.05$ compared to adult $2.5 \% \& 3.5 \% \mathrm{ED}$.

$b_{p}<0.05$ compared to adolescent $2.5 \% \mathrm{ED}$

${ }^{c} p<0.05$ compared to adolescent $2.5 \% \mathrm{ED}$ and adult $3.5 \% \mathrm{ED}$. 


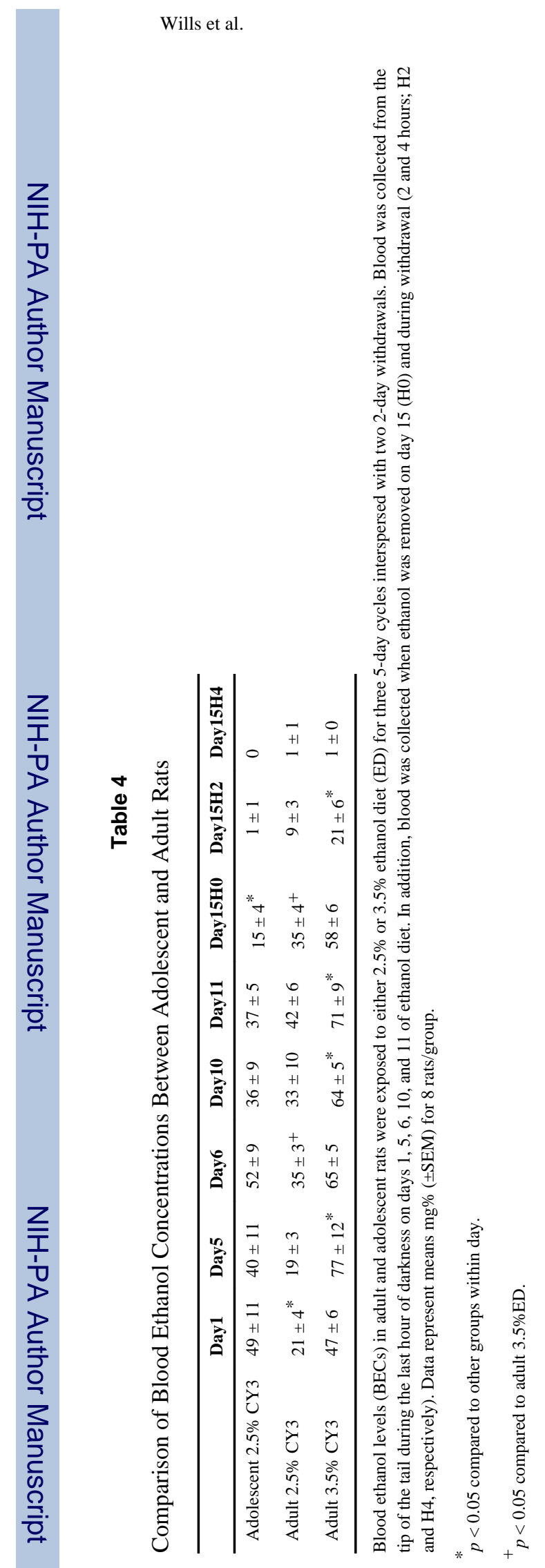

Alcohol Clin Exp Res. Author manuscript; available in PMC 2010 March 30. 